\title{
Overt reanalysis strategies and eye movements during the reading of mild garden path sentences
}

\author{
ENRIQUE MESEGUER and MANUEL CARREIRAS \\ Universidad de La Laguna, Tenerife, Spain \\ and \\ CHARLES CLIFTON, JR. \\ University of Massachusetts, Amherst, Massachusetts
}

\begin{abstract}
In an eye movement experiment, we examined the use of reanalysis strategies during the reading of locally ambiguous but globally unambiguous Spanish sentences. Among other measures, we examined regressive eye movements made while readers were recovering in reading mild garden path sentences. The sentences had an adverbial clause that, depending on the mood (indicative vs. subjunctive) of the subordinate clause verb, could attach high (to the main verb of the sentence) or low (to the verb in the subordinate clause). Although Spanish speakers favor low attachment, the high attachment version was quite easy to understand. Readers predominately used two alternative strategies to recover from the mild garden path in our sentences. In the more common reanalysis strategy, their eyes regressed from the last region (disambiguation+1) directly to the main verb in the sentence. Following this, they reread the rest of the sentence, fixating the next region and the adverb (the beginning of the ambiguous part of the sentence). Less frequently, readers regressed from the last region (disambiguation +1 ) directly to the adverb. We argue that both types of strategies are consistent with a selective reanalysis process as described by Frazier and Rayner (1982).
\end{abstract}

During the last few years, psycholinguists interested in sentence processing have paid considerable attention to when and how readers reanalyze garden path sentences (i.e., those in which the syntactic structure assigned to the initial portion of a sentence is syntactically inconsistent with following words). Reanalysis has been defined in various ways (see Fodor \& Inoue, 1998; Gorrell, 1998; Lewis, 1998; Pritchett, 1992; Sturt \& Crocker, 1998; Sturt, Pickering, \& Crocker, 1999, 2000). For our purposes, we will assume that at some points in comprehending a sentence, a reader might assign a unique structural analysis to the sentence up to the point in question. If later information forces the reader to attempt to revise that analysis, we say that reanalysis has occurred. We assume that parsing processes result in systematic initial preferences for certain analyses, and we will concentrate our attention on cases in which reanalysis requires the rejection of the normally preferred initial analysis and its replacement by a normally unpre-

This research was supported by Grants 1FD97-0927 and BSO20000862 from the FEDER and the Spanish Ministry of Science and Technology to the University of La Laguna and by Grant HD-18708 from the National Institutes of Health to the University of Massachusetts. The authors thank Keith Rayner and Lyn Frazier for their suggestions on earlier versions of this paper. Correspondence should be addressed to E. Meseguer, Departmento de Psicología Cognitiva, Universidad de La Laguna, 28205 La Laguna, Tenerife, Spain (e-mail: emesegue@ull.es). ferred analysis (recognizing that these initial preferences are not inviolable).

Theoretical and empirical research on this topic has focused on two points: the characteristics of the garden path sentences that affect their difficulty, and the nature of the reanalysis process. Researchers have studied a variety of factors that affect processing difficulty, including plausibility (Pickering \& Traxler, 1998; Rayner, Carlson, \& Frazier, 1983), prosodic information (Bader, 1998), length of the ambiguous region (Ferreira \& Henderson, 1991b) or length of one of the sites to attach to the ambiguous phrase (Thornton, MacDonald, \& Arnold, 2000), and argument structure frequency (Ferreira \& Henderson, 1991a), among others. In addition, several models of the reanalysis process have been developed in order to explain which actual process readers use when they find a nonpreferred disambiguation (Fodor \& Inoue, 1994; Gorrell, 1995; Lewis, 1998; Pritchett, 1992; Sturt \& Crocker, 1998).

One question of interest is whether the processes that support reanalysis are reflected in overt eye movements when a reader is faced with the nonpreferred disambiguation of an unconscious, easy, or mild garden path sentence (cf. Gorrell, 1995; Pritchett, 1992). Such eye movements could serve the function of obtaining new information from the text or confirming previously encoded information, or they could simply reflect the tendency of the eyes to look at what a person is thinking about (Cooper, 1974; Richardson \& Spivey, 2000; Spivey \& Geng, 2001). We will return to the discussion of this contrast at the end of the paper. However this question is resolved, overt eye movements 
could in principle give us information about what information is involved in reanalysis and how that information is represented and accessed during reanalysis.

It is possible, of course, that reanalysis strategies are covert. Overt reanalysis would be implicated if the eyes moved back to a previous point in the sentence to recover an alternative attachment site and reconstruct or repair the current partial phrase marker (CPPM). Covert analysis would be suggested if readers continued to fixate the disambiguation point and recovered the possible alternative attachment site from memory. As Lewis (1998) pointed out, both types of reanalysis have assets and liabilities. Overt reanalysis could reduce memory load by letting the visible text serve as a memory, but consulting the text could be slow. Covert reanalysis could speed reanalysis by eliminating the time needed to reacquire information from the sentence, but it might place large demands on memory and processing to retain and locate stored information.

If overt reanalysis is observed, one can ask how the reader's eyes are guided. As Frazier and Rayner (1982) pointed out, the eyes of the reader can behave in three different ways: They can be intelligentlyled to some critical point in the sentence (selective reanalysis), they can return to just the beginning of the sentence to reread it until they find the point at which the incorrect alternative was taken ( forward reanalysis), or they can go back through the whole sentence from the disambiguation point to find the alternative attachment site (backward reanalysis). Frazier and Rayner found some evidence for both selective and forward reanalysis. However, owing to the small number of regressions that their readers made, Frazier and Rayner could not carry out statistical analyses to provide evidence for the proposed strategies. Since Frazier and Rayner described these three types of strategies, there has been little research in which the trajectories of eye movements have been used to make inferences about reanalysis.

The possibility of an overt selective reanalysis strategy is interesting because it would indicate that a reader maintains a mental record of the relevant points of parsing ambiguity that can guide regressive eye movements. Selective overt reanalysis would be efficient in that the reader would not have to reread the whole sentence because he or she would know exactly where to redirect his or her eyes. It presumably requires more memory than does forward or backward reanalysis, enough to keep the record of the site where the critical point was. If memory demands are light enough, however (perhaps because the critical point is near the disambiguation point), covert reanalysis may be possible. This could result in increased first-pass reading time (summed fixation duration from first entering a region to leaving it) on the disambiguating region without frequent regressions to earlier parts of the sentence. Easy covert reanalysis is likely in Examples 1 and 3, shown in Figure 1. As noted by Gorrell (1998), there is no intuitive evidence for reanalysis cost in these examples. The tree diagrams in Examples 2 and 4 indicate that a simpler structure must be replaced by a more complex one, but according to models like Gorrell's (1998), the amount of memory load needed to revise the CPPM is small and the reanalysis operations needed are not demanding.

On the other hand, if the revision is more complicated (but still possible), or if the critical point is too far from the disambiguation point, readers might have to use an overt reanalysis strategy. They might invoke such a strategy only after attempting to use a covert reanalysis strategy, or immediately upon reading the disambiguating material. In both cases, regressive eye movements would occur. Only in the former case would first-pass reading time for a region be lengthened compared with a sentence in which reanalysis is not needed (see Rayner \& Sereno, 1994, for relevant discussion).

To identify the type of overt reanalysis strategy that readers use requires the examination of the pattern of regressive eye movements. The strategy cannot be identified on the basis of the usual measures of reading time such as first-pass time, total time (the sum of all fixation times in a region), or second-pass time (the sum of all fixations in a region after leaving the region and then reentering it).

The research reported here extends Frazier and Rayner's (1982) attempt to provide evidence for a selective reanalysis process, in which the eyes regress from a disambiguating region directly to the earlier region whose structural analysis must be revised. We present an experiment in which we examined the reanalysis strategies that readers use when they have to read locally ambiguous sentences that are disambiguated in the nonpreferred manner. The participants' eye movements were recorded for a relatively large number of sentences with a clearly identifiable region involved in reanalysis. This served to identify the actual pattern of how the participants regressed to and reread earlier parts of the locally ambiguous sentences that were disambiguated toward the nonpreferred sense.

We used a type of temporary ambiguity in which disambiguation relies on the use of verbal moods in Spanish to express the actual or potential occurrence of the events (Table 1). The ambiguity consists of the two possible attachment sites of an adverbial phrase (AdvP): the main verb (VP1) of the sentence, which was always a verb of communication in the indicative mood, or the verb in a sentential complement (VP2), which was always in the subjunctive. The sentences were ambiguous up to the verb of the AdvP. Disambiguation was accomplished by manipulating the mood of this verb. If it was in the indicative mood (entraron in Table 1, Version A [came in]), the adverbial phrase had to attach to an indicative verb, VP1 (dijo, [told $]$ ). This indicated that the action expressed in VP2 should be done unconditionally. If the verb of the AdvP was in the subjunctive mood (entraran in Table 1, Version B [come in]), the adverbial phrase had to attach to a subjunctive verb, VP2 (se levantaran, [to stand up]). This indicated that the action expressed in VP2 had to be done only when the condition included in the AdvP takes place.

Meseguer (1995) used self-paced reading measures to experimentally demonstrate easier processing of sentences that were resolved in favor of VP2 attachment of the AdvP. Existing theories provide various reasons for why attach- 
(1) John ate the apple and the pear.

(2) a.

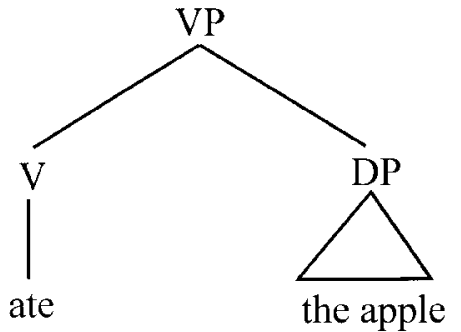

b.

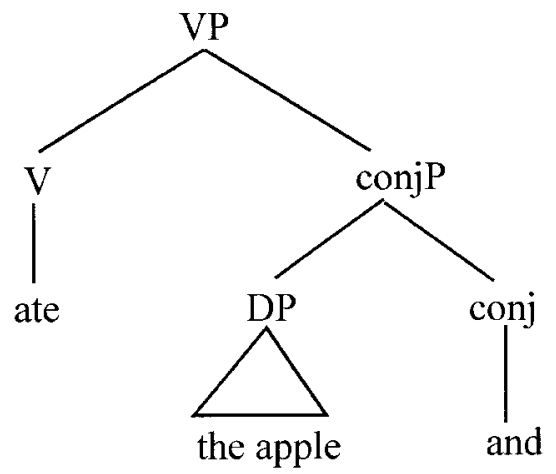

b.

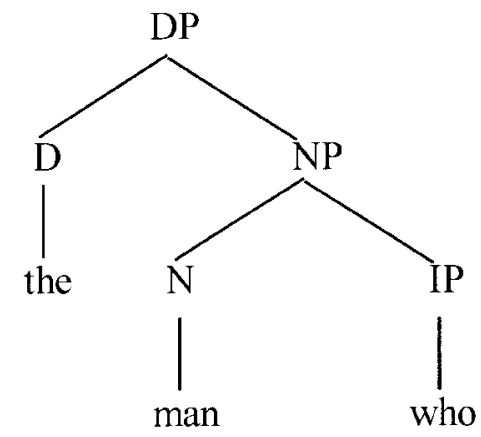

Figure 1. Tree diagrams for covert reanalysis of syntax.

ment to VP2 should be preferred. Frazier's $(1978,1987)$ garden path theory offers the late closure strategy: If possible, keep adding elements to the current clause or phrase. Frequency-based models (e.g., Jurafsky, 1996; MacDonald, Pearlmutter, \& Seidenberg, 1994) or probabilistic serial models (Traxler, Pickering, \& Clifton, 1998) can base their predictions on the probable fact that VP2 attachments are more frequent than VP1 attachments, if only because it is more common to have the adjunct clause at the beginning of the sentence when it modifies VP1. Although the preference for VP2 attachment is real, it does not imply the total collapse of the reading process when the reader encounters a VP1 attachment. Readers facing this last condition rarely report a conscious effort to understand it, indicating the general success of whatever reanalysis strategies they use to reanalyze sentences like those that we examined. What interests us here is what strategies readers use to reanalyze such sentences when they encounter the nonpreferred disambiguation.

Up to this point, we have assumed that reanalysis is a costly process that requires one to consult short-term memory or actually search visual information either to diagnose the nature of the analysis error (Fodor \& Inoue, 1994, 1998) or to repair it (cf. the discussions of backtracking and repair parsing in Lewis, 1998). In fact, the type of reanalysis required in the sentences we examined was not the difficult and disruptive activity that theories of reanalysis like those cited above attempt to explain. It is not difficult to diagnose the nature of the analysis error in our sentences (cf. Fodor \& Inoue, 1994), nor do repair operations such as Lewis's (1998) snip operation (which removes a constituent from the CPPM so that other parsing operators can reattach it elsewhere) fail in them. The cost that has been observed in sentences with the sort of attachment ambiguity we examined (Meseguer, 1995) reflects the normal operation of the diagnosis or repair processes these theories describe, not their failure. We thus expected the eye movement behavior observed in our experiment to inform us about how reanalysis processes are successfully applied, not about how they go astray.

\section{METHOD}

\section{Participants}

Forty-four undergraduate students of the University of La Laguna received course credit for their participation in this experiment. All of the participants were native Spanish speakers with normal uncorrected vision, and they were naive with respect to the purposes of the experiment.

\section{Design and Materials}

Forty-eight groups of sentences similar to the ones in Table 1 were constructed. The design of the experiment was a $2 \times 2$ with repeated measures on the factors form of the subjunctive verb (VP2) before the disambiguation (-ara vs. -ase inflection) and attachment site of the adverbial phrase (VP1, with the verb of the adverbial 
Table 1

Sample Sentences Used in the Experiment, With Syntactic Analysis Indicated By [ ]

A. Unpreferred (High Attachment to VP1)
El profesor [VP1 dijo [CP que los alumnos
[VP2 se levantaran del asiento]] [AdvP cuando los directores entraron en la clase.]]
The teacher [VP1 said [CP that the students
[VP2 had to stand up from their seats]] [AdvP when the directors came INDIC into the room.]]
B. Preferred (Low Attachment to VP2)
El profesor [VP1 dijo [CP que los alumnos
[VP2 se levantaran del asiento [AdvP cuando los directores entraran en la clase.]]]]
The teacher [VP1 said [CP that the students
[VP2 had to stand up from their seats [AdvP when the directors come SUBJ into the room.]]]]
Note-Presentation line breaks were where they appear in the table.

clause in the indicative mood, vs. VP2, with the verb of the adverbial clause in the subjunctive mood). We manipulated the surface form of VP2, which was always in the subjunctive mood, to control for the possibility that similarity of phonological form between VP2 and the verb in the AdvP could facilitate reading of VP2 attachment sentences. In Spanish, the subjunctive mood has two possible terminations: -ara, -ase for singular, and -aran, -asen for plural, with slight variations, depending on the conjugation of the verb (first, second, or third; although in many cases second and third conjugations have similar inflections) and its regularity. Despite the fact that the -ara form is more frequent than the -ase form, both are absolutely equivalent and interchangeable, and both are commonly used. The -ara form was always used for a subjunctive verb in the VP2-attached AdvP (see Table 1, Version B). Its reading could in principle be speeded if VP2, the verb in the preceding clause, was also - ara in form. This possibility was examined by using the -ase inflection for VP2 half the time. Thus, each sentence had four conditions: -ara termination of the VP2 verb, VP1 attachment; - ara termination of VP2, VP2 attachment; -ase termination VP2, VP1 attachment; -ase termination of VP2, VP2 attachment.

The participants read 12 experimental sentences in each condition. The four experimental conditions were counterbalanced so that each participant read each experimental sentence in just one condition. Since the length of some of the experimental sentences exceeded the width of the screen on which they were presented ( 80 characters), all of them were split into two lines, as is shown in Table 1. The first line always contained the head NP, the main verb (V1), and the first part of the complement clause, including the head (que [that]) and an NP (the subject of this clause). The second line always contained the verb of the complement clause (V2 in the subjunctive mood with -ara or -ase termination), the adverb cuando [when], an NP (the subject of the adverbial clause), the verb of the adverbial clause (V3 in the indicative or the subjunctive mode: the disambiguation), and a PP or an adverb (an adjunct to the last verb). We split the sentences in this way in order to avoid having the head of the adverbial phrase at the beginning or the end of a line. The NP subject of the adverbial clause was always plural. This was done so that the length of the verb in this clause in both attachment conditions would be the same, because the number agreement between a singular subject and the verb would produce different lengths in the indicative and subjunctive forms of the verb: el director llegó versus el director llegara in the sentences in Table 1 . In some of the sentences ( 25 out of 48 ), additional text (an NP, an adjective or a PP) was needed after the verb of the complement clause (del asiento [ from their seats] in our example) in order to make them more natural. This region, present only in some of the sentences, will not be analyzed in the Results section. (The complete list of materials can be found at http://www-unix. oit. umass.edu/ cec/about.html.)

The 48 experimental sentences were presented to the participants randomly intermixed with 96 unrelated sentences. These filler sen- tences were presented in one ( 40 sentences), two ( 40 sentences), or three (16 sentences) lines of text.

\section{Apparatus}

The sentences were presented in lowercase letters (with uppercase letters where appropriate) on a video screen interfaced with a PCcompatible computer. The participants were seated $70 \mathrm{~cm}$ away from the monitor, and three characters equaled $1^{\circ}$ of visual angle. A Fourward Technologies Dual Purkinje Eyetracker interfaced with the computer was used to record the participants' eye movements. The eyetracker had a resolution of 10 arcmin (half a character). Viewing was binocular, but eye position was recorded from the right eye. The signal from the eyetracker was sampled every millisecond by the computer.

\section{Procedure}

When a participant arrived for the experiment, he or she was seated in front of the monitor. A chinrest and a headrest with a securing strap were used to prevent head movements. The participants were asked to silently read the sentences displayed on the monitor. They were told that they would be questioned about the sentences and that they should read for comprehension. Once the instructions were given, the eyetracking system was calibrated, which took about $5 \mathrm{~min}$. Each participant then read 10 practice sentences in order to become familiar with the procedure. Prior to reading each sentence, the participants were instructed to look at each of five boxes in the middle of the screen, corresponding to the position of the first line of the sentence. A red dot, which indicated the participant's fixation location, indicated to the experimenter whether the eyetracker was correctly calibrated. The experimenter then pressed a button to display the sentence. True/false questions were asked after half of the total amount of items and after half of the experimental items. The question in an experimental item did not involve the attachment site of the AP, and it was the same for both VP1 and VP2 attachment conditions. For example, for the sentences included in Table 1, the question was Los alumnos tenían que ponerse de pie [The students had to stand up], which is true for both conditions. In this sentence, a question like Los alumnos tenían que quedarse sentados [The students had to remain seated] would have been false.

When the experimenter pressed the button to begin a trial, a sentence immediately appeared on the screen. After reading the sentence, the participant pressed a response button, which resulted either in the presentation of a question or in that of the row of calibrationcheck boxes for the next trial. When a question appeared on the screen, the participant had to press one of two buttons to answer "true" or "false" (left for true, right for false). Half of the questions required a "true" answer, and half required a "false" answer. No feedback was given about question-answering accuracy. After the participants completed each third of the experiment, they were given a break. After the break, the equipment was recalibrated, and the ex- 


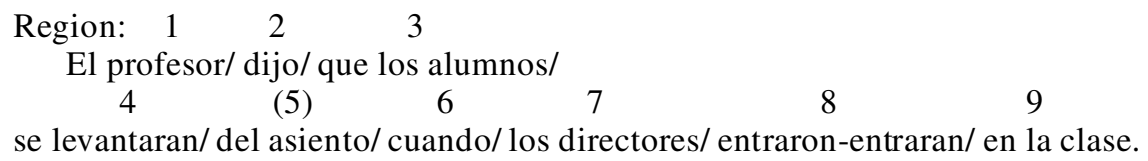

Figure 2. Sentence divided into nine regions for analysis.

periment was resumed at the point at which it had been interrupted. Apart from the two routine recalibrations, if a failure in calibration was detected prior to any sentence, the experimenter recalibrated the apparatus.

\section{RESULTS}

The mean question-answering accuracy rate was $92 \%$. The participants had a maximum of 12 errors out of the total 72 comprehension questions in the experiment, which represents a minimum accuracy rate of $83 \%$. In the experimental sentences, the participants had a maximum of 5 errors out of the 24 comprehension questions, which represents a minimum accuracy rate of $79 \%$. Reading data were analyzed for each sentence, whether or not its question was answered correctly.

\section{Eye Movement Analysis}

For analysis, the sentences were divided into nine regions as in Figure 2. The means for several measures of eye movements (defined below) in each of these nine regions are shown in Table 2. The -ara versus -ase inflection of the second verb (V2) factor did not yield any reliable interaction with attachment site of the AdvP in any of the measures or in any region, demonstrating that the effects of the second factor could not be due to phonological similarity. Therefore, for the sake of clarity in exposition, the V2 inflection factor will not be discussed further.

First fixation duration is defined as the duration of the first fixation that the participants made when they looked for the first time at a region (eliminating trials on which they looked at a later region before fixating the region in question). First-pass reading time is the sum of the dura-

Table 2

Means of Eye Movement Measures by Region and AdvP Attachment Site Condition

\begin{tabular}{|c|c|c|c|c|c|c|c|c|c|c|}
\hline \multirow[b]{2}{*}{ Measure } & \multirow[b]{2}{*}{$\begin{array}{l}\text { Attachment } \\
\text { Site } \\
\end{array}$} & \multicolumn{9}{|c|}{ Region } \\
\hline & & $\begin{array}{c}1 \\
\text { NP1 } \\
\end{array}$ & $\begin{array}{c}2 \\
\mathrm{~V} 1 \\
\end{array}$ & $\begin{array}{c}3 \\
q u e \mathrm{NP} 2 \\
\end{array}$ & $\begin{array}{c}4 \\
\mathrm{~V} 2 \\
\end{array}$ & $\begin{array}{c}(5) \\
\text { (text) }\end{array}$ & $\begin{array}{c}6 \\
\text { Adverb } \\
\end{array}$ & $\begin{array}{c}7 \\
\text { NP3 } \\
\end{array}$ & $\begin{array}{c}8 \\
\text { V3(D) } \\
\end{array}$ & $\begin{array}{c}9 \\
\mathrm{PP} \\
\end{array}$ \\
\hline $\begin{array}{l}\text { First fixation } \\
\quad(\mathrm{msec})\end{array}$ & $\begin{array}{l}\text { VP1 } \\
\text { VP2 }\end{array}$ & & & & $\begin{array}{l}280 \\
276\end{array}$ & $\begin{array}{l}270 \\
273\end{array}$ & $\begin{array}{l}253 \\
251\end{array}$ & $\begin{array}{l}244 \\
245\end{array}$ & $\begin{array}{l}263 \\
265\end{array}$ & $\begin{array}{l}248 \\
245\end{array}$ \\
\hline $\begin{array}{l}\text { First pass } \\
(\mathrm{msec})\end{array}$ & $\begin{array}{l}\text { VP1 } \\
\text { VP2 }\end{array}$ & $\begin{array}{l}714 \\
726\end{array}$ & $\begin{array}{l}394 \\
406\end{array}$ & $\begin{array}{l}737 \\
737\end{array}$ & $\begin{array}{l}576 \\
559\end{array}$ & $\begin{array}{l}418 \\
437\end{array}$ & $\begin{array}{l}278 \\
280\end{array}$ & $\begin{array}{l}490 \\
487\end{array}$ & $\begin{array}{l}423 \\
426\end{array}$ & $\begin{array}{l}678 \\
682\end{array}$ \\
\hline $\begin{array}{l}\text { Regressions path time } 1 \\
\quad(\mathrm{msec})\end{array}$ & $\begin{array}{l}\text { VP1 } \\
\text { VP2 }\end{array}$ & & & & $\begin{array}{l}620 \\
589\end{array}$ & $\begin{array}{l}570 \\
567\end{array}$ & $\begin{array}{l}356 \\
370\end{array}$ & $\begin{array}{l}595 \\
605\end{array}$ & $\begin{array}{l}490 \\
512\end{array}$ & $\begin{array}{l}1,501^{*} \\
1,376^{*}\end{array}$ \\
\hline $\begin{array}{l}\text { Regressions path time } 2 \\
\quad(\mathrm{msec})\end{array}$ & $\begin{array}{l}\text { VP1 } \\
\text { VP2 }\end{array}$ & & & & $\begin{array}{l}599 \\
576\end{array}$ & $\begin{array}{l}493 \\
510\end{array}$ & $\begin{array}{l}304 \\
312\end{array}$ & $\begin{array}{l}543 \\
545\end{array}$ & $\begin{array}{l}462 \\
477\end{array}$ & $\begin{array}{l}867 \\
851\end{array}$ \\
\hline $\begin{array}{l}\text { Regressions path time } 3 \\
\quad(\mathrm{msec})\end{array}$ & $\begin{array}{l}\text { VP1 } \\
\text { VP2 }\end{array}$ & & & & $\begin{array}{l}21 \\
13\end{array}$ & $\begin{array}{l}77 \\
56\end{array}$ & $\begin{array}{l}51 \\
58\end{array}$ & $\begin{array}{l}51 \\
60\end{array}$ & $\begin{array}{l}29 \\
34\end{array}$ & $\begin{array}{l}634^{*} \\
525^{*}\end{array}$ \\
\hline $\begin{array}{l}\text { First pass } \\
\quad \text { regressions out (\%) }\end{array}$ & $\begin{array}{l}\text { VP1 } \\
\text { VP2 }\end{array}$ & & & & $\begin{array}{l}1.75 \\
1.55\end{array}$ & $\begin{array}{l}17.57 \\
12.88\end{array}$ & $\begin{array}{l}11.11 \\
11.64\end{array}$ & $\begin{array}{l}11.13 \\
10.82\end{array}$ & $\begin{array}{l}7.16 \\
7.45\end{array}$ & $\begin{array}{l}56.17 * \\
51.25 *\end{array}$ \\
\hline Regressions in $(\%)$ & $\begin{array}{l}\text { VP1 } \\
\text { VP2 }\end{array}$ & $\begin{array}{l}36.4 \\
36.22\end{array}$ & $\begin{array}{l}20.34 \dagger \\
17.77 \dagger\end{array}$ & $\begin{array}{c}12.5 \\
11.65\end{array}$ & $\begin{array}{l}21.76 \\
19.14\end{array}$ & $\begin{array}{l}11.95 \\
11.91\end{array}$ & $\begin{array}{l}13.5 \\
11.51\end{array}$ & $\begin{array}{l}11.72 \\
11.82\end{array}$ & $\begin{array}{l}21.5 \\
19.3\end{array}$ & \\
\hline $\begin{array}{l}\text { First pass movement } \\
\text { from Region } 9\end{array}$ & $\begin{array}{l}\text { VP1 } \\
\text { VP2 }\end{array}$ & $\begin{array}{l}3.59 \\
3.57\end{array}$ & $\begin{array}{l}2.09 * \\
1.36^{*}\end{array}$ & $\begin{array}{l}1.93 \\
1.77\end{array}$ & $\begin{array}{l}0.71 \\
0.7\end{array}$ & $\begin{array}{l}0.25 \\
0.18\end{array}$ & $\begin{array}{l}0.62 * \\
0.21 *\end{array}$ & $\begin{array}{l}0.84 \\
0.69\end{array}$ & $\begin{array}{l}5.59 \\
5.32\end{array}$ & \\
\hline $\begin{array}{l}\text { Proportion of FPM } \\
\text { from Region } 9\end{array}$ & $\begin{array}{l}\text { VP1 } \\
\text { VP2 }\end{array}$ & $\begin{array}{l}.43 \\
.48\end{array}$ & $\begin{array}{l}.26^{*} \\
.18^{*}\end{array}$ & $\begin{array}{l}.24 \\
.24\end{array}$ & $\begin{array}{l}.2 \\
.21\end{array}$ & $\begin{array}{l}.05 \\
.05\end{array}$ & $\begin{array}{l}.18^{*} \\
.06^{*}\end{array}$ & $\begin{array}{l}.21 \\
.16\end{array}$ & & \\
\hline $\begin{array}{l}\text { Total movements } \\
\text { from Region } 9\end{array}$ & $\begin{array}{l}\text { VP1 } \\
\text { VP2 }\end{array}$ & $\begin{array}{l}3.82 \\
3.75\end{array}$ & $\begin{array}{l}2.3^{*} \\
1.41^{*}\end{array}$ & $\begin{array}{l}2.09 \\
1.89\end{array}$ & $\begin{array}{l}0.71 \\
0.75\end{array}$ & $\begin{array}{l}0.25 \\
0.23\end{array}$ & $\begin{array}{l}0.62 * \\
0.25 *\end{array}$ & $\begin{array}{l}0.98 \\
0.75\end{array}$ & $\begin{array}{l}5.78 \\
5.5\end{array}$ & \\
\hline $\begin{array}{l}\text { Proportion of TM } \\
\text { from Region } 9\end{array}$ & $\begin{array}{l}\text { VP1 } \\
\text { VP2 }\end{array}$ & $\begin{array}{l}.43 \\
.47\end{array}$ & $\begin{array}{l}.26 * \\
.18^{*}\end{array}$ & $\begin{array}{l}.26 \\
.24\end{array}$ & $\begin{array}{l}.19 \\
.22\end{array}$ & $\begin{array}{l}.05 \\
.06\end{array}$ & $\begin{array}{l}.18^{*} \\
.06^{*}\end{array}$ & $\begin{array}{l}.24 \\
.19\end{array}$ & & \\
\hline Second pass 1 (msec) & $\begin{array}{l}\text { VP1 } \\
\text { VP2 }\end{array}$ & $\begin{array}{l}154 \\
152\end{array}$ & $\begin{array}{r}107 \\
95\end{array}$ & $\begin{array}{l}129 * \\
104 *\end{array}$ & $\begin{array}{l}129 \\
114\end{array}$ & $\begin{array}{l}46 \\
39\end{array}$ & $\begin{array}{l}65^{*} \\
49 *\end{array}$ & $\begin{array}{l}87 \\
75\end{array}$ & $\begin{array}{l}118 \\
111\end{array}$ & \\
\hline Second pass 2 (msec) & VP1 & 154 & 69 & 43 & 80 & 19 & 34 & 42 & 78 & \\
\hline & VP2 & 152 & 59 & 41 & 72 & 18 & 28 & 41 & 80 & \\
\hline Second pass 3 (msec) & $\begin{array}{l}\text { VP1 } \\
\text { VP2 }\end{array}$ & & $\begin{array}{l}39 \\
37\end{array}$ & $\begin{array}{l}88^{*} \\
65^{*}\end{array}$ & $\begin{array}{l}50 \\
42\end{array}$ & $\begin{array}{l}27 \\
22\end{array}$ & $\begin{array}{l}32 * \\
21 *\end{array}$ & $\begin{array}{l}45 \\
35\end{array}$ & $\begin{array}{l}40 \dagger \\
31 \dagger\end{array}$ & \\
\hline $\begin{array}{l}\text { Total time } \\
\text { (msec) }\end{array}$ & $\begin{array}{l}\text { VP1 } \\
\text { VP2 }\end{array}$ & $\begin{array}{l}850 \\
870\end{array}$ & $\begin{array}{l}532 \\
525\end{array}$ & $\begin{array}{l}927 \dagger \\
896 \dagger\end{array}$ & $\begin{array}{l}687 \dagger \\
657 \dagger\end{array}$ & $\begin{array}{l}577 \\
563\end{array}$ & $\begin{array}{l}356 \dagger \\
344 \dagger\end{array}$ & $\begin{array}{l}625 \\
606\end{array}$ & $\begin{array}{l}575 \\
573\end{array}$ & $\begin{array}{l}830 \\
818\end{array}$ \\
\hline
\end{tabular}

Note_* Reliable effects in both by participants and by items analyses. † Means in which the effects were reliable only by participants or by items. For more details about statistical reliability, see Table 3. 
tions of the fixations made in a region from when the participantsfirst fixated in the region until they left the region in a backward direction or looked at a later region. Total time is the sum of the durations of all the fixations made in a region. Regression path time 1 is the summed fixation duration from when the region was first fixated until the eyes first moved past the region; this includes first-pass time, time spent in previous parts of the sentence following any regressive eye movements, and time due to refixations coming from the left before the eyes moved past the region. This measure can be divided into two other measures: regression path time 2 , which includes only firstpass time and time due to refixations in the region coming from the left before the eyes went past the region, and $r e$ gression path time 3 , which includes only time spent in the previous parts of the sentence between when the region was first entered and when the eyes went past it (which could take the value of zero). First-pass regressions out includes the percentage of trials in which at least one regression was made from a given region to previous parts of the sentence prior to leaving that region in a forward direction. Regressions-in includes the percentage of trials in which a given region received at least one regression from later parts of the sentence. First-pass movements (FPM) from Region 9 are the frequency of regressive eye movements made from Region 9 to each of the other regions, counting only the first regression from Region 9. The proportion of FPM from Region 9 for Regions 1, 2, and 3 (regions in the first line of the sentences) was calculated by dividing the number of eye movements from Region 9 to each region by the total number of movements to the whole first line. ${ }^{1}$ For Regions 4, 5, 6, and 7 (in the second line), the number of eye movements to each region was divided by the sum of movements to the four regions. Total movements (TM) from Region 9 includes the total frequency of saccadic movements made from Region 9 to each other region, including regressions after the initial one. The proportion of TM was calculated in the same manner as the proportion of FPM. Second-pass time 1 represents the summed duration spent refixating each region once the eyes had moved out of it. This measure can be divided into second-pass time 2, which represents the summed duration of the fixations in which the region was entered from the right, and second-pass time 3, which represents the summed duration of the fixations in which the region was reentered from the left after the eyes had left the region. Trials with no fixations in the region being analyzed were eliminated in calculating all measures except the three second-pass measures, in which nonfixated regions contributed durations of zero. ${ }^{2}$

Table 3 shows the results, both by participants and by items, of the statistical analyses made for each measure in each region of interest. All of them are one-way analyses of variance in which the only factor was attachment site of the final AdvP (VP1 vs. VP2).

There is clear evidence in several, but not all, measures for a VP2 attachment preference. The first fixation and first-pass measures were not longer in any region when a sentence was disambiguated toward VP1 rather than toward VP2. No measure of reading time in the disambiguating region, $\mathrm{V} 3$, showed a significant garden-path effect apart from second-pass 3, where the nonpreferred VP1 attachment averaged $40 \mathrm{msec}$ as compared with $31 \mathrm{msec}$ for VP2 attachment. However, the regression path duration was longer for VP1 than for VP2 attachment in the region following disambiguation (1,501 vs. $1,376 \mathrm{msec}$ for regression path time 1). Regressions out of this region were similarly more frequent for VP1 than for VP2 attachment (56\% vs. $51 \%$ ). Finally, the total time and second-pass measures provided evidence for processing difficulty in several early regions following VP1 attachment.

Evidence for VP1 attachment difficulty thus appeared in measures that are sensitive to the number and duration of regressive eye movements from the region following the disambiguating region. As discussed earlier, this suggests the operation of overt reanalysis. Detailed examination of the landing sites of regressions and related measures provides information about the nature of this reanalysis. Some evidence for intelligent or selective reanalysis can be found in the apparent fact that regressive eye movements into Region 2, V1, were more frequent for VP1 than for VP2 attachment sentences (significant only by items). More convincingly, the first-pass movement measures indicate that readers' eyes more frequently moved directly from the last region of the sentence to the main verb, V1, following disambiguation in favor of VP1 attachment than following VP2 attachment. Most relevantly, 26\% of the first-pass regressions from Region 9 to the first line landed directly on the first verb, V1, in the VP1 attachment condition, as compared with $18 \%$ in the VP2 attachment condition. The absolute frequency of such regressions (2.09 vs. 1.36) was also higher for VP1 than for VP2 attachment. This difference may reflect an intelligent reanalysis process, since the AdvP presumably had to be reanalyzed as being attached to the phrase with V1 as its head in the VP1 attachment condition.

However, given that the main verb is normally near the beginning of the sentence, just after NP1, this result could be artifactual. Perhaps readers faced with a VP1 attachment disambiguation were simply trying to reach the initial part of the sentence, but their eyes fell short, landing on the verb. This possibility seems rather unlikely, given that the beginning of the VP1 region ranged between 5 and 36 characters from the left of the screen in the experimental materials. However, to evaluate this possibility carefully, two additional analyses were conducted. Both analyses required new segmentations of the sentences. In the first one, the first region was defined as the first 10 characters of each sentence. If readers were trying to get to the beginning of the text, independently of its content, the proportion of all first-line movements from the last region that went to this new first region should show the same pattern of results as we found in the V1 region: more movements in the VP1 attachment condition than in the VP2 


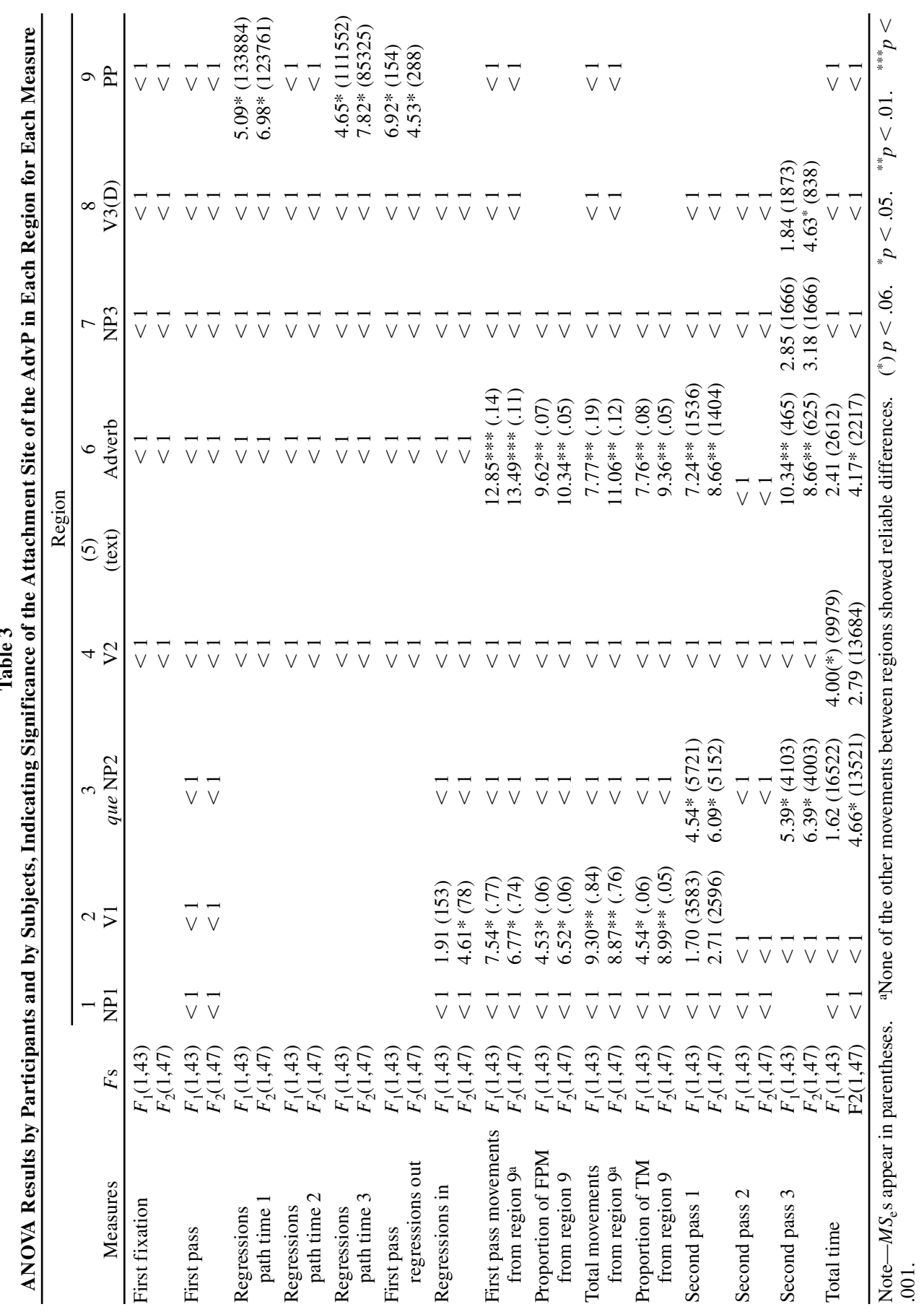


attachment condition. However, the proportions of firstpass movements from the last region to the 10-character first region for the two conditions were .35 for the VP1 attachment condition and .37 for the VP2 attachment condition (both $F_{1}$ and $F_{2}<1$ ).

Second, the first line of every sentence was divided into as many five-character regions as possible. The number of movements from Region 9 to each of these regions was correlated with the proportion of characters in the region that belonged to $\mathrm{V} 1$ (so if all five characters were included in the verb, the proportion was 1.0 ; four of the five characters, .8 , etc.). The correlation in the VP1 attachment condition $(r=.17)$ was significantly higher than in the VP2 attachment condition $(r=.07 ; t=1.989, p<.05)$, and the former correlation but not the latter was significantly greater than zero $(z=3.753, p<.01$ and $z=$ $1.479, p>.1)$. This result suggests that one determinant of whether a regression was made from Region 9 to a region near the beginning of the sentence was the content of this region (how much of the verb it included), not its position in the first line of the sentences. We thus conclude that the reader directed his or her eyes to V1 more frequently following disambiguation to VP1 than to VP2 attachment, indicating an intelligent overt reanalysis process.

An additional point of interest in the data is the high frequency of first-pass and total eye movements from Region 9 to the adverb that heads the ambiguously attached AdvP. Both the absolute number and the proportion of relevant regressive movements that went directly to the adverb were higher following VP1 than VP2 disambiguation ( 0.62 vs. 0.21 movements; $18 \%$ vs. $6 \%$ ). This finding suggests a second form of intelligent reanalysis. Rather than the eyes returning to the point at which the AdvP had to be attached, they returned to the head of the phrase whose reattachment had to be revised. Second-pass reading times were also higher in this region following VP1 than VP2 disambiguation ( $65 \mathrm{vs} .49 \mathrm{msec}$ for all second-pass times; 32 vs. $21 \mathrm{msec}$ for just second-pass times when the region was reentered from a position to its left).

There were more total movements than first-pass movements from the last region to the main verb [3.71 vs. 3.45; $F_{1}(1,43)=5.22, M S_{\mathrm{e}}=0.09, p<.05 ; F_{2}(1,47)=8.52$, $\left.M S_{\mathrm{e}}=0.05, p<.01\right]$, indicating the presence of multiple regressions from Region 9 to the main verb. This difference was marginally larger for VP1 than for VP2 sentences $\left[0.21\right.$ vs. $0.05 ; F_{1}(1,43)=5.51, M S_{\mathrm{e}}=0.03, p<$ .05 ; but $\left.F_{2}(1,47)=2.34, M S_{\mathrm{e}}=0.06, p>.10\right]$. In the VP1 attachment condition, the difference between total and first-pass movements was significant $\left[F_{1}(1,43)=6.07\right.$, $M S_{\mathrm{e}}=0.09, p<.02 ; F_{2}(1,47)=6.01, M S_{\mathrm{e}}=0.08, p<$ $.02]$, whereas the differences in the VP2 attachment condition were not significant $\left[F_{1}(1,43)=2.05, M S_{\mathrm{e}}=0.02\right.$, $\left.p>.1 ; F_{2}(1,47)=2.04, M S_{\mathrm{e}}=0.02, p>.1\right]$. There were no significant differences between total and first-pass movements from the last region to the adverb $\left[F_{1}(1,43)=\right.$ $2.05, M S_{\mathrm{e}}=0.01, p>.1 ; F_{2}(1,47)=3.13, M S_{\mathrm{e}}=0.01$, $p=.08]$. The interaction in this region was not significant either $\left[F_{1}(1,43)=2.05, p>.1 ; F_{2}<1\right]$.

\section{DISCUSSION}

The first conclusion we can draw from our results is that readers have a preference for VP2 attachment. This preference was observed in several regions in 9 out of the 15 measures taken into account: regression paths 1 and 3 , regressions out, first-pass and total movements, proportions of first-pass and total movements from Region 9, and second passes 1 and 3. Further, there are traces of this preference in two other measures, total time and regressionsin. But since this preference was already observed (in selfpaced reading) by Meseguer (1995), the important issue here is the interpretation that we can extract from the effects we have observed.

As can be seen in Table 1, neither of the two early stage measures, first fixation and first-pass time (Rayner, Sereno, Morris, Schmauder, \& Clifton, 1989), showed effects in the attachment site of the AdvP manipulation, either in the disambiguating region (V3) or in the following region (PP). As we suggested in the introduction, longer times for VP1 than for VP2 attachment in the disambiguating region or the next region would have made us conclude that the participants in our experiment were at least trying to reanalyze covertly. However, the lack of effects that we obtained in these measures does not permit us, in principle, to rule out covert reanalysis. We should note one possible confounding factor: The indicative verb form used for the normally nonpreferred VP1 disambiguation was more frequent than the subjunctive form used for the normally preferred VP2 disambiguation. The verbs in the indicative mood had an average frequency of 13 occurrences per million (maximum 52, minimum 0 ), and the same verbs in the subjunctive mood had an average frequency of 2 occurrences per million (maximum 12, minimum 0; Sebastián-Gallés, Martí, Carreiras, \& Cuetos, 2000). Faster reading time for more frequent forms could have obscured a potential covert reanalysis effect.

Regardless of the validity of the suggestion of a frequency confound, it is possible that covert reanalysis processes occurred but were too quick to affect the eye movement record. The fact that regressions from the disambiguating region were very infrequent $(7 \%)$ and occurred on only about $50 \%$ of the trials from the last region of the sentence indicates that overt reanalysis is not always necessary.

Although the actual evidence that the nonpreferred version of our sentences can be reanalyzed covertly is minimal, there is good evidence for a selective overt reanalysis strategy. The readers took longer from first entering the immediate postdisambiguating region, Region 9, to leaving it (and terminating the sentence display) when the AdvP was attached to VP1 rather than to VP2. Both regression path durations 1 and 3 showed this effect, whereas regression path duration 2 did not. The latter measure included only time spent inside Region 9. Its nonsignificance suggests that most of the time spent recovering from a misanalysis was spent outside the region at which reanalysis was initiated. 
Evidence about where the eyes fixated during reanalysis comes from the regressions-in measure for Region 2 (the main verb) and especially from the frequencies and proportions of first-pass and total movements from Region 9. These effects, together with the absence of attachment effects in the movements from the last region to a 10-character region at the beginning of the sentence, and the significant tendency that we found for more movements into early regions that contained the main verb than into regions that did not, demonstrate that the readers' eyes sometimes returned directly to the main verb of the sentence when they found a phrase that had to be attached to it instead of being attached to the more recent verb. There was also a significantly greater number and proportion of regressive movements made from the last region to the head of the AdvP (the adverb cuando [when]) in the VP1 attachment condition than in the VP2 attachment condition. This difference held for both first-pass and total movements. This effect suggests a second reanalysis strategy that readers used when the verb in the AdvP invalidated the initial VP2 attachment. In this case, they may have remembered the potential attachment site, but since they were revising the attachment of a whole phrase, they were thinking about that phrase and their eyes moved back to its head.

As noted by a reviewer of a previous version of this paper, one must not get too carried away by the fact that regressive eye movements to critical regions in sentences with normally unpreferred VP1 attachments were more frequent than in sentences with normally preferred VP2 attachments. After all, over half the fixations in the final region of the sentence resulted in regressions in the VP2 attachment condition, and only about $10 \%$ more regressions occurred in the VP1 attachment condition. Only this excess $10 \%$ can be attributed directly to reanalysis processes. Still, as the reviewer went on to note, one can make a rough estimate of the frequency with which the eyes went to an appropriate region on the trials in which a reanalysis-triggered regression took place by examining how the differences between the VP1 and VP2 conditions in frequencies of first-pass regressions varied across regions. As can be seen in Table 2, Region 1 (for example) exhibits a difference of only 0.02 regressions between VP1 and VP2 sentences (3.59 vs. 3.57). Region 2, on the other hand, exhibits a difference of 0.73 regressions (2.09 vs. 1.36). In fact, considering the total sum of all such differences (Regions 1-8), Regions 2 and 6 (the initial verb and the adverb) were responsible for $63 \%$ of the total (40\% in Region 2, 23\% in Region 6). One can reasonably conclude that a clear majority of all reanalysistriggered regressions went directly to one of the two appropriate landing sites.

The fact that there were more total than first-pass movements (especially when a sentence was disambiguated to VP1 attachment) made from Region 9 to V1, but not from Region 9 to the adverb, suggests that the readers may have used two distinct strategies to reanalyze. When an overt reanalysis was needed, sometimes readers' eyes went back to the main verb, and at other times, they went to the adverb. In the VP1 attachment condition, the number of total eye movements from the last region to the main verb was higher than the number of first-pass movements. This might have arisen because when the readers returned to the main verb, they sometimes returned to it more than once. But the absence of differences between first-pass and total movements from the last region to the adverb suggests that the strategies are independent. Sometimes readers' eyes went to the main verb (and sometimes they went there more than once), and other times they went to the adverb (and they went only once).

Alternatively, it is possible that what we consider to be two strategies are parts of the same strategy. Normally, when an overt reanalysis is needed, readers may return directly to the main verb to reattach to it the phrase that previously was attached to the more recent verb. However, this strategy by itself does not explain why there were more total than first-pass movements to V1. Such a difference could arise if the eyes first move from Region 9 to the adverb, only later moving to V1 after returning to Region 9. Perhaps the readers sometimes needed to deattach the AdvP from VP2 prior to attaching it to VP1. Their eyes might then regress first to the adverb, then return to Region 9, and then regress to the main verb. This application of the strategy is illustrated in Movements 1, 2 , and 3 of Figure $3 \mathrm{~A}$. This pattern would imply that when there was a first-pass movement from the last region to the adverb, there should be at least one movement from the last region to the first verb in the total movement count that was not present in first-pass movements. But our data demonstrated that this occurred only three times out of the total of 2,112 trials in the experiment.

We conclude that normally the two strategies are independent, as is illustrated in Figure 3B. Here, when an overt reanalysis strategy is needed, participants' eyes generally return to the main verb of the sentence (Movement 1a), but occasionally they go instead to the adverb (Movement 1b). The first is a completely selective overt reanalysis strategy: Readers return to the main verb presumably to pick up more information about the new attachment site of the AdvP, sometimes returning to the disambiguating region and back to the main verb more than once. The second strategy can be seen as a kind of semicovert strategy. The readers' eyes are intelligently led to the adverb, a concrete and critical part of the sentence. However, readers can remember what the main verb was and can accomplish the reattachment process without further returns to the adverb.

In a complementary way, second-pass times inform us, although roughly, about how the readers proceeded after their eyes went back to the main verb or to the adverb. The most informative second-pass effects were those found once the region was left forward, considering only refixations coming from the left side of that region (second pass 3). The longer second-pass 3 times in Region 3 (que NP2) for VP1 versus VP2 sentences suggest that the participants kept reading after they had reached the main verb in the VP1 (nonpreferred) attachment condition. The appearance of a similar effect on the adverb following nonsignificant differences in Regions 4 and 5 suggests 
A

3

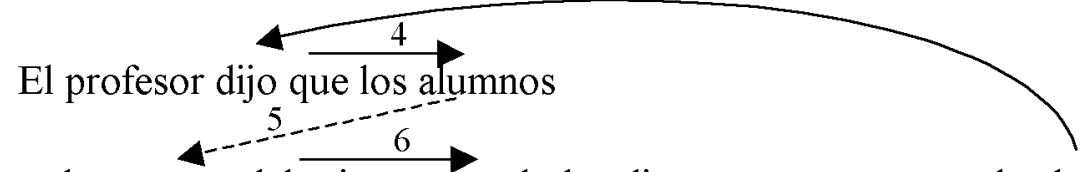

se levantaran del asiento cuando los directores entraron en la clase.

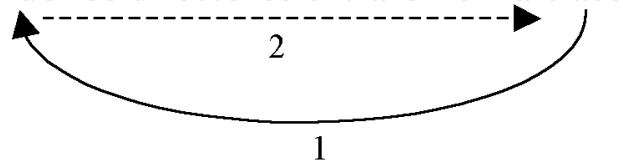

B

la

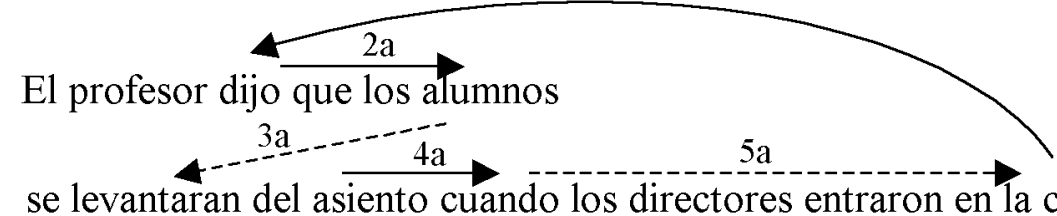

se levantaran del asiento cuando los directores entraron en la clase.

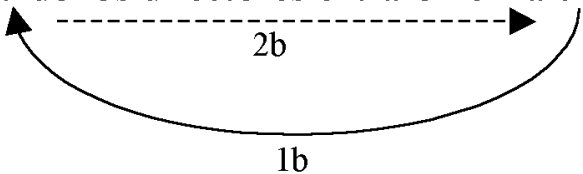

Figure 3. The two possible patterns of eye movements involved in reanalysis that would explain the results of the experiment. As is explained in the text, Pattern A turns out to be implausible or very rare. Pattern $B$ is the most plausible. Solid arrows represent those movements for which there is reliable evidence. Dashed arrows represent those movements that are infrequent or for which there is no reliable evidence.

that the readers may have spent extra time rereading the adverb after rereading V1 in the VP1 attachment condition. Hypothetically, it could be that when the readers encountered the nonpreferred disambiguation and an overt reanalysis was needed, their eyes were directed to the main verb to pick up more information about the possibility of attaching the AdvP to it. After reaching the verb, they kept reading the first line of the sentence, and they passed to some point of the second line between the beginning of it and the adverb. As their eyes arrived at the adverb, the rereading process was slowed in order to complete the reanalysis process attaching the AdvP to the main verb (see Figure 3B).

In the introduction, we briefly raised the question of what function eye movements back to the alternate attachment site might play in reanalysis (cf. Kennedy, 1983). It is tempting to suggest that readers remember the position of the initial verb but have to check its form to confirm its appropriateness as an attachment site. It is possible, however, that readers are not actually acquiring information from the first verb. There is evidence that the eyes commonly move to the positions of objects that are being talked about or queried in discourse comprehension, memory, and reasoning tasks (e.g., Cooper, 1974; Kennedy, 1983; Richardson \& Spivey, 2000; Spivey \& Geng, 2001), even when the object being queried has been removed from the visual display. A comparable process may occur during sentence reanalysis: The reader retrieves the alternate attachment site during what is basically covert reanalysis, and the eyes spontaneously return to its position, perhaps to focus attention on what had appeared there but not to gather more information about it. We can raise one argument against this proposal. If reanalysis is basically covert, there is no reason why readers should keep reading the rest of the sentence after refixating the initial verb. However, this was a moderately common pattern, as suggested by the fact that there were more refixations coming from the left (second pass 3 ) in Region 3 (que NP2) in the high-attachment condition (VP1) than in the lowattachment condition (VP2). We acknowledge, though, that additional research (perhaps manipulating the availability of information at the site of the first verb during regressions to that site) is needed to securely answer the question of the function of direct regressions to alternate attachment sites.

Another question that must be left to future research is the precise nature of the representation of the first verb, $\mathrm{V} 1$, that allows the eyes to move directly back to it when reanalysis is needed. We have spoken as if the eyes move back to it because it is an alternate attachment site for the AdvP, presumably noted during the parsing process. This may be attributing too much intelligence to the reanalysis system. It is possible that the eyes move back to it simply because it is the main verb of the sentence and as such, the head of the sentence. Alternatively, the eyes may move back to it because it matches the verb of the AdvP in mood; in cases in which the AdvP is attached into VP1, the verb of the AdvP is indicative and so is the main verb. 
In either case, it may be important that all 48 sentences were similar in where the critical VP appeared (but not identical, as noted earlier; and note further, there were 96 filler sentence that were quite highly variable in where the initial VP appeared). The data we present here do not allow us to choose among these possibilities, but they do show that the question of precisely what guides the eyes in intelligent reanalysis can be effectively addressed by close examination of the eye movement record.

To summarize, we have provided statistically sound evidence for the sort of selective reanalysis process proposed by Frazier and Rayner (1982). We have argued that readers can apply two different selective reanalysis strategies in order to reanalyze the nonpreferred version of a sentence in which an AdvP can attach to the main verb of the sentence (the nonpreferred analysis) or to the verb in a sentential complement (the preferred analysis). The eye movements involved in both strategies are summarized in Figure 3B. In the most commonly used strategy (the one signaled with arrows 1a to 5a in Figure 3B), the eyes of the reader are intelligently guided to critical points of the sentence, possibly to pick up information about the new attachment site of the AdvP. Less commonly, readers followed a different reanalysis strategy (arrows $1 \mathrm{~b}$ and $2 \mathrm{~b}$ in Figure 3B). This strategy is not completely overt because it does not imply going back to the alternative attachment site. The reader probably retrieves the alternative attachment site from memory. Rather, the eyes move to the adverb because the reader was thinking about the AdvP and trying to detach it from the original attachment to VP2.

\section{REFERENCES}

BADER, M. (1998). Prosodic influences on reading syntactically ambiguous sentences. In J. Fodor \& F. Ferreira (Eds.), Reanalysis in sentence processing (pp. 1-46). Dordrecht: Kluwer.

COOPER, R. M. (1974). The control of eye fixation by the meaning of spoken language: A new methodology for the real-time investigation of speech perception, memory, and language processing. Cognitive Psychology, 6, 61-83.

Ferreira, F., \& Henderson, J. M. (1991a). How is verb information used during syntactic parsing? In G. B. Simpson (Ed.), Understanding word and sentence (pp. 305-330). Amsterdam: Elsevier.

Ferreira, F., \& Henderson, J. M. (1991b). Recovery from misanalyses of garden-path sentences. Journal of Memory \& Language, 30, 725 745.

FodOR, J. D., \& INOUE, A. (1994). The diagnosis and cure of garden paths. Journal of Psycholinguistic Research, 23, 407-434.

Fodor, J. D., \& InOUE, A. (1998). Attach anyway. In J. D. Fodor \& F. Ferreira (Eds.), Reanalysis in sentence processing (pp. 427-473). Dordrecht: Kluwer.

FrAZIER, L. (1978). On comprehending sentences: Syntactic parsing strategies. Unpublished doctoral dissertation, University of Connecticut, Storrs.

FrAZIER, L. (1987). Sentence processing: A tutorial review. In M. Coltheart (Ed.), Attention and performance (pp. 559-586). Hillsdale, NJ: Erlbaum.

FraZier, L., \& RAYNER, K. (1982). Making and correcting errors during sentence comprehension: Eye movements in the analysis of structurally ambiguous sentences. Cognitive Psychology, 14, 178-210.

Gorrell, P. (1995). Syntax and parsing. Cambridge: Cambridge University Press.

GORRELL, P. (1998). Syntactic analysis and reanalysis in sentence processing. In J. D. Fodor \& F. Ferreira (Eds.), Reanalysis in sentence processing (pp. 201-245). Dordrecht: Kluwer.
JURAFSKY, D. (1996). A probabilistic model of lexical and syntactic access and disambiguation. Cognitive Science, 20, 137-194.

KENNEDY, A. (1983). On looking into space. In K. Rayner (Ed.), Eye movements in reading: Perceptual and language processes (pp. 237251). New York: Academic Press.

LEWIS, R. L. (1998). Reanalysis and limited repair parsing: Leaping off the garden path. In J. D. Fodor \& F. Ferreira (Eds.), Reanalysis in sentence processing (pp. 247-286). Dordrecht: Kluwer.

MacDonald, M. C., Pearlmutter, N. J., \& Seidenberg, M. S. (1994). Lexical nature of syntactic ambiguity resolution. Psychological Review, 101, 676-703.

MeSeguer, E. (1995). Estrategias de procesamiento sintáctico en español. Unpublished doctoral dissertation, Universidad de La Laguna, Tenerife, Spain.

Pickering, M. J., \& Traxler, M. (1998). Plausibility and the recovery from garden paths: An eyetracking study. Journal of Experimental Psychology: Learning, Memory, \& Cognition, 24, 940-961.

PritcheTt, B. L. (1992). Grammatical competence and parsing performance. Chicago: University of Chicago Press.

Rayner, K., CARlson, M., \& Frazier, L. (1983). The interaction of syntax and semantics during sentence processing: Eye movements in the analysis of semantically biased sentences. Journal of Verbal Learning \& Verbal Behavior, 22, 358-374.

RAYNer, K., \& SERENo, S. C. (1994). Regressive eye movements and sentence parsing: On the use of regression-contingent analyses. Memory \& Cognition, 22, 281-285.

Rayner, K., Sereno, S. C., Morris, R. K., Schmauder, A. R., \& Clifton, C. J. (1989). Eye movements and on-line language comprehension processes. Language \& Cognitive Processes, 4, SI21SI49.

Richardson, D. C., \& Spivey, M. J. (2000). Representation, space, and Hollywood Squares: Looking at things that aren't there anymore. $\mathrm{Cog}$ nition, 76, 269-295.

Sebastián-Gallés, N., Martí, M. A., Carreiras, M., \& Cuetos, F. (2000). LEXESP: Léxico informatizadodel español. Barcelona: Edicions Universitat de Barcelona.

SpIVEY, M. J., \& GENG, J. J. (2001). Oculomotor mechanisms activated by imagery and memory: Eye movements to absent objects. Psychological Research, 65, 235-241.

StURT, P., \& CROCKER, M. (1998). Generalized monotonicity for reanalysis models. In J. D. Fodor \& F. Ferreira (Eds.), Reanalysis in sentence comprehension (pp. 365-400). Dordrecht: Kluwer.

Sturt, P., Pickering, M. J., \& Crocker, M. W. (1999). Structural change and reanalysis difficulty in language comprehension. Journal of Memory \& Language, 40, 136-150.

Sturt, P., Pickering, M. J., \& Crocker, M. W. (2000). Search strategies in syntactic reanalysis. Journal of Psycholinguistic Research, 29, 183192.

Thornton, R., MacDonald, M. C., \& Arnold, J. E. (2000). The concomitant effects of phrase length and informational content in sentence comprehension. Journal of Psycholinguistic Research, 29, 194-204.

Traxler, M., Pickering, M., \& Clifton, C., Jr. (1998). Adjunct attachment is not a form of lexical ambiguity resolution. Journal of Memory \& Language, 39, 558-592.

\section{NOTES}

1. A few participants made no regressions from Region 9 to the first line. Rather than eliminating these participants from the calculation of proportions, we entered zero values for them. Thus, the reported proportions do not quite sum to 1.0.

2. This large number of correlated measures does raise the possibility of spurious significance. We believe that this concern is mitigated by the practice in eye tracking research of looking for coherent and interpretable patterns of results across related measures rather than simply attempting to find some significant effects.

(Manuscript received April 24, 2001; revision accepted for publication October 14, 2001.) 